\title{
Development of Air-atomizing Mist Nozzles and Mist Cooling System for Continuous Casting*
}

\author{
By Masashi MITSUTSUKA, ${ }^{* *}$ Yozo Fukuhisa, ${ }^{* *}$ Makoto WAKE, ${ }^{* * * *}$ \\ Masaki OKAJIMA,***** Nagao MIYASHITA ${ }^{* * * * * *}$ and Yasuo TAKEDA T $^{* * * * * * *}$
}

\begin{abstract}
Synopsis
The use of air-atomizing mist nozzle for the secondary cooling of continuous casting machine results in the following advantages over the conventional water spray nozzle: less longitudinal surface cracks and higher temperature of cast slabs, wide control range of cooling, and prevention of nozzle clogging. The air injection to the water spray nozzle is also good for preventing nozzle clogging.

The authors have developed a few types of air-atomizing nozzles and their application techniques, including methods of injection, for the secondary cooling system of the slab casters.

Discussed here are structural and fluidic features of the newly developed mist nozzles and the air-injection type spray nozzle with reference to some technical points concerning the new cooling system and the operational results.
\end{abstract}

\section{Introduction}

Among the important issues of continuous casting are the prevention of internal and surface defects of cast slabs, stabilization of caster equipment and operation, and recovery of heat possessed in the slab in the next step. Reduction in the surface cracks of slabs and delivery of hot slabs from the castert are prerequisites for the recovery of heat, and prevention of nozzle clogging in the secondary cooling zones (spray cooling zones) of the caster is a prerequisite for the stabilization of caster operation.

Most of the surface cracks in the slab are formed when cracks occur originally in the mold and then propagate as the slab is intensely cooled and reheated repeatedly in the secondary cooling zones. ${ }^{1-3)}$ In the secondary cooling zones, the slab is intensely cooled in the portions where it is exposed to impinging spray water and is in contact with the guide rolls (pocketed water cooling and roll contact cooling). The following measures are effective in alleviating the intense cooling of the slab in these localized areas:

1) Uniformly apply cooling water to the all surfaces of slab or uniform contact of cooling water to the all surfaces of slab

2) Allow no cooling water to be pocketed by the rolls in contact with the slab

3) Prevent heat transfer from the slab to the rolls.

In flat spray cooling, pressure-atomized water droplets first impinge concentratedly on a narrow area of the slab and then run down along the length of the slab and are pocketed by the rolls. This compares with mist cooling in which air-atomized water droplets first impinge on a wide area of the slab and then mostly flow across the width of slab and are pocketed little by the rolls. When mist cooling is employed, therefore, there is a possibility of requirements 1) and 2) being satisfied at the same time. ${ }^{4-6)}$

Mildly cooling the slab in the secondary cooling zones is effective in reducing the surface cracks and recovery of slab heat. When nozzles with small outlet holes are used for mild spray cooling, they are liable to clog. As the outlets of new mist nozzles (of the premix type) are larger than those of conventional spray nozzles by the amount of discharged air, nozzle clogging does not increase with decreasing water volume, as compared with the conventional spray nozzles.

H. Schrewe investigated the application of mist cooling to the secondary cooling zones of continuous slab casters to prevent cooling water from being pocketed by the rolls. ${ }^{7,8}$ In his case, the mist stream is discharged toward each edge of the slab from a nozzle installed at the transverse center of the slab. The present authors studied the mist cooling method whereby the mist stream is perpendicularly impinged on the slab surface as is the case with conventional spray cooling.

The development steps and operational results of the mist nozzles and mist cooling system for continuous slab casters are reported here. For the effect of mist cooling on slab quality, the reader is referred another report. ${ }^{6)}$

\section{Develoment of Mist Nozzle and Air-injection Nozzle}

\section{Concepts behind Nozzle Development}

The authors developed a mist nozzle to simultaneously satisfy all the operational and equipment requirements described in the foregoing section and an air-injec-

\footnotetext{
* Originally published in Tetsu-to-Hagané, 70 (1984), 694, in Japanese. English version received on April 22, 1985; accepted in the final form on July 12, 1985 . (C) 1985 ISIJ

** R \& D Laboratories-III. Nippon Steel Corporation, Edamitsu, Yawatahigashi-ku, Kitakyushu 805.

*** Plant Engineering \& Technology Bureau, Nippon Steel Corporation, Otemachi, Chiyoda-ku, Tokyo 100.

**** Oita Works, Nippon Steel Corporation, Oaza Nishinosu, Oita 870.

***** Sakai Works, Nippon Steel Corporation, Chikko Yawatamachi, Sakai 590.

****** Kimitsu Works, Nippon Steel Corporation, Kimitsu, Kimitsu 299-11.

******* Hirohata Works, Nippon Steel Corporation, Fuji-cho, Hirohata-ku, Himeji 671-11.

$+\quad$ Slabs are delivered at high temperature to the next step to make the most of the heat possessed in them.
} 
tion nozzle to mainly secure freedom from clogging.

The requirements for the mist nozzle are summarized as follows:

1) Atomization of cooling water into a fine mist $\rightarrow$ Uniform cooling of slab

2) Wide-angle discharge of mist stream $\rightarrow$ Reduction in number of nozzles installed

3) Increase in size of nozzle outlet $\rightarrow$ Reduction in nozzle clogging and increase in discharged water volume range

4) Decrease in size of nozzle $\rightarrow$ Installation of nozzle between rolls.

The requirements for the air-injection nozzle are the same as mentioned in 2) to 4) above. The technological ideas adopted to develop the nozzles that would meet these requirements are illustrated in Fig. 1. A premix nozzle and a commercial flat spray nozzle were taken as candidates for the mist nozzle and air-injection nozzle, respectively.

\section{Development of Premix Mist Nozzle}

\section{Development Steps of Mist Nozzle}

The development steps of the mist nozzle are shown in Fig. 2. As the initial aim was to cool the entire

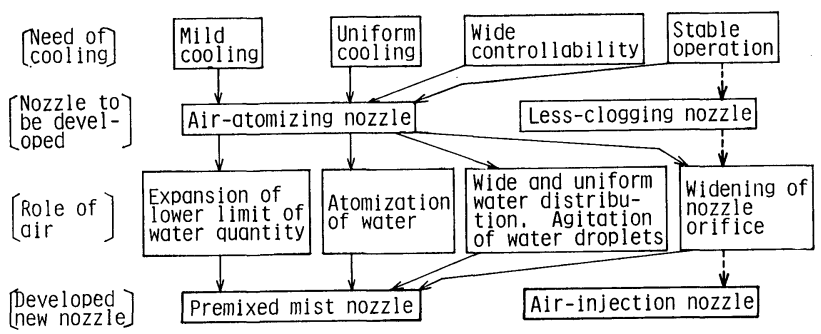

Fig. 1. The technological thoughts to develop new nozzles for the secondary cooling of continuous casting machine. width of the slab with a mist stream discharged from one nozzle, the authors' thought was directed toward widening the mist stream as far as possible. For this purpose, it is suited to collide two high-speed airwater mixture streams in opposite directions as with the nozzles of Figs. 2 (1) and (2). This collision method was the starting point for the development of the mist nozzle.

When the nozzles outlined in Fig. 2 are installed on a continuous slab caster, the nozzle arrangements are shown in Fig. 3. Large nozzles are arranged as shown in Fig. 3(1), so that most of the mist stream directly impinges on the rolls. To avoid this shortcoming, the nozzles must be reduced to such a size as to be capable of being installed between the rolls. The premix method that uses compressed air was thus adopted to decrease the size of the nozzle and pipe line. Finally, the small mist nozzle schematicall illustrated in Fig. 4 was developed. Mist nozzles in service now somewhat vary from caster to caster; however, they are similar in basic design.

2. Water Flux and Droplet Diameter Distributions of Mist Stream

The water flux and droplet diameter distributions of the mist stream discharged from practical nozzles are given in Fig. 5. The half-value width of the water flux distribution of the mist stream is about $120 \mathrm{deg}$ in terms of angle (2 $\theta$ in Fig. 5 (1) and the water droplets are mostly 20 to $60 \mu \mathrm{m}$ in diameter, about one-tenth of the diameter of water droplets discharged from the spray nozzle (200 to $600 \mu \mathrm{m}$ in Fig. 5 (4)).

\section{Development of Air-injection Nozzle}

The method of injecting compressed air into the water supply pipe was developed to prevent the clogging of flat spray nozzles conventionally used in

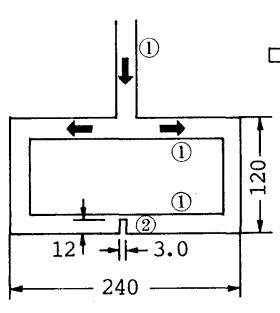

(1) Original nozzle

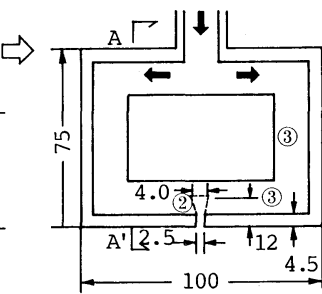

(2) Wide angle nozzle

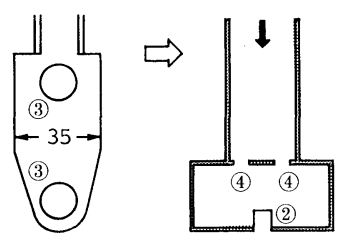

(3) Small and simplified
nozzle

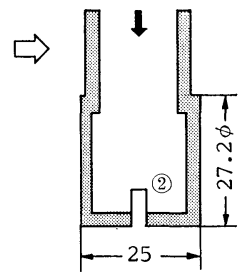

(4) Practical nozzle (An example)
(1): Pipe (ID 12.7, OD 17.3)
(2): Tip orifice
(3): Drilled hole $(15 \phi)$

Fig. 2. Development steps of mist nozzles.
(4): Drilled hole

I: Flow of air and water Unit: $\mathrm{mm}$

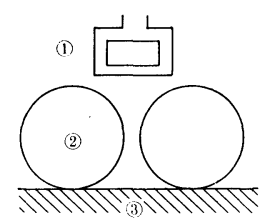

(1) Large nozzle

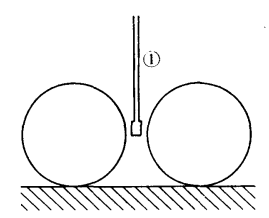

(2) Small nozzle
(1): Nozzle

(2): Roll

(3): Slab

Fig. 3. Installation of mist nozzles.

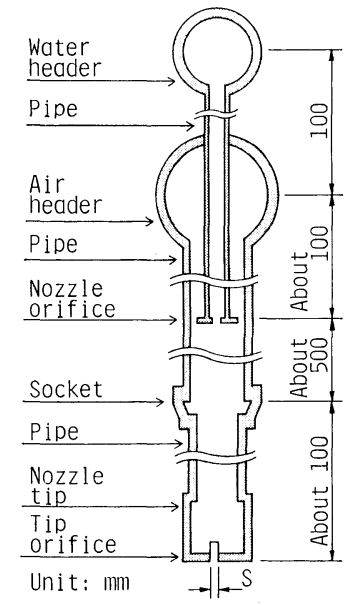

Fig. 4. Schematic diagram of a newly developed practical mist nozzle. 

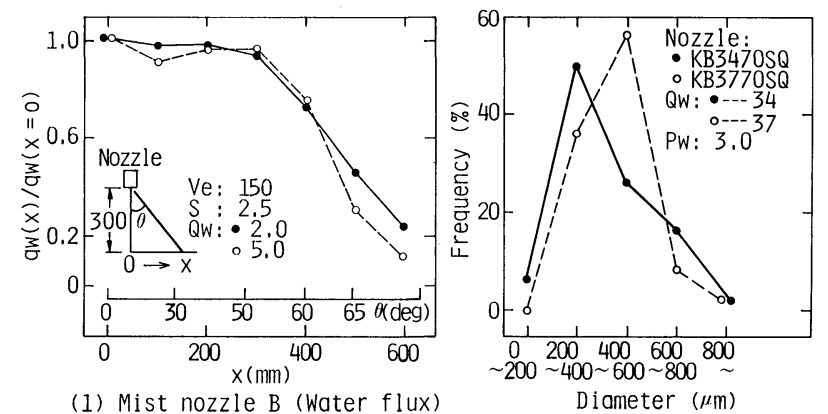

(1) Mist nozzle B (Water flux)

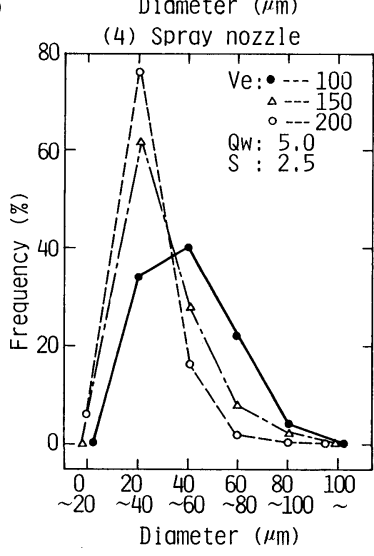

(2) Mist nozzle $A$

(3) Mist nozzle B

$Q_{a}, Q_{w}:$ Flow rate of air and water ejected from a nozzle

$q_{w}(x)$ : Amount of collected water at $X=X$

$A / W$ : Mass flow ratio of $Q_{a} / Q_{w}$

$V_{e}:$ Exit speed of air $(\mathrm{m} / \mathrm{s})$

$S:$ See Fig. 4

$P_{w}:$ Water pressure in header $\left(\mathrm{kgf} / \mathrm{cm}^{2}-\mathrm{G}\right)$

Fig. 5. Water flux and water droplet size distribution.

(Practical mist nozzles and full cone spray nozzles)

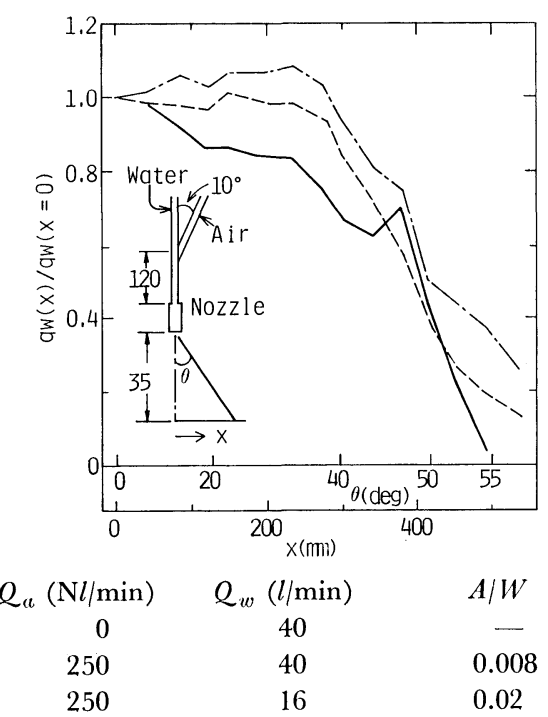

Nozzle: Water $120 \mathrm{l} / \mathrm{min}$ and spray angle $115 \mathrm{deg}$ at $3 \mathrm{kgf} / \mathrm{cm}^{2}-\mathrm{G}$

Fig. 6. Water flux distribution in spray ejected from a practical air-injection nozzle.

large numbers in the secondary cooling zones of slab casters. When the water volume is the same, the air injection allows the size of the nozzle outlet to be

increased by such a degree as to correspond to the amount of air injected. The high-speed discharge of air helps to remove the deposits from the hole of the nozzle outlet by the air stream.

The water flux distribution of the spray discharged from the air-injection nozzle is shown in Fig. 6. It is evident from the diagram that the air injection slightly widens the water flux distribution of the spray. When visually observed, the diameter of the water droplets in the spray is relatively large at the major-axis center of the elliptic cross section and is small at the major-axis edge of the elliptic cross section.

The amount of injected air is smaller than that of the mist nozzle and the air-water mass flow ratio $A / W$ is about 0.005 to 0.05 . The optimum air flow rate depends on the target value for the prevention of nozzle clogging, the size of the nozzle outlet, quality of water, cost of compressed air, etc. The air should be injected as close as possible to the nozzle to prevent the pulsation of the spray.

\section{Development of Water and Air Supply System for Mist Cooling}

\section{Uniform Supply of Cooling Water to Headers}

When the caster is of the bending type, a head difference exists among the water headers in the respective zones of the curved section and causes variation of water flow rate from header to header. To avoid this variation, each water header was equipped with a flow control orifice (header orifice) on the water supply side. The effect of the header orifice is shown in Fig. 7. In this example, the lower limit (set point) of water flow discharged from each nozzle is 0.5 and $0.8 \mathrm{l} / \mathrm{min}$ for the loose and fixed surfaces of the slab, respectively, and the difference in head between the top and bottom headers is $1.8 \mathrm{~m}$. The ratio of the water flow rate discharged from the top nozzles $Q_{w 2}$ to the water flow rate preset for the zone $Q_{w 1}$ is set to 0.8 or more as the design criterion.

According to Fig. 7, the $Q_{w 2} / Q_{w 1}$ ratio for the same value of $Q_{w 1}$ increases with decreasing orifice diameter. The orifice diameter that satisfies $Q_{w 2} / Q_{w 1}$ $\geqq 0.8$ for the lower limit of $Q_{w 1}$ is $4 \mathrm{~mm}$ for the loose surface and $5 \mathrm{~mm}$ for the fixed surface.

\section{Pulsation Phenomenon of Mist Stream}

When the water flow rate $Q_{w}$ discharged from the mist nozzle is decreased under the constant air flow rate $Q_{a}$, pulsation of mist stream will occur. This pulsation phenomenon was observed by the transparent plastic models. When $Q_{w}$ is small and the water supply pipe pressure $P_{w}$, is nearly equal to the air-water premix section pressure $P_{m}\left(P_{w^{\prime}}\right.$ and $P_{m}$ measured in the positions shown in Fig. 8), small variations in the pipe line pressure and other factors break the balance between $P_{w}$ and $P_{m}$. As a result, the pressure difference between $P_{w^{\prime}}$ and $P_{m}$ periodically fluctuates between plus and minus values. When $P_{w^{\prime}}>P_{m}$, the water is discharged from the 


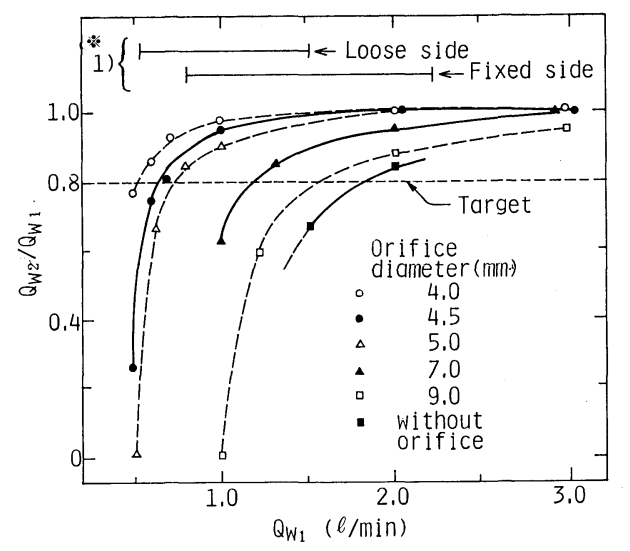

$※ 1)$ : Required water flow ranges of the nozzles in this zone

$Q_{w 2}$ : Water flow ejected from a nozzle at the highest level in this zone

$Q_{w 1}:$ Average water flow in this zone

Maximum header level

difference in this zone: $1800 \mathrm{~mm}$

Fig. 7. Effect of the header orifice on the uniformity of water flow ejected from practical nozzles at various levels of the secondary cooling zone.

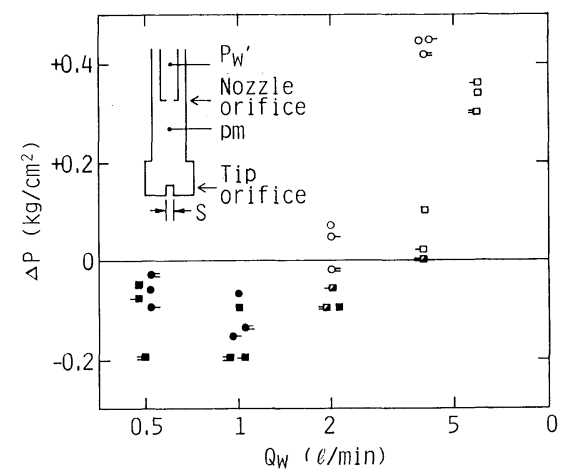

\begin{tabular}{|l|c|c|}
\hline \multirow{2}{*}{ Pulsation } & \multicolumn{2}{|c|}{$S(\mathrm{~mm})$} \\
\cline { 2 - 3 } & 3.0 & 4.0 \\
\hline Existent & $\bullet$ & $\square$ \\
Indistinct & 0 & $\square$ \\
None & 0 & $\square$ \\
\hline
\end{tabular}

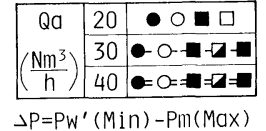

$\triangle P=P W^{\prime}(\operatorname{Min})-P m(\operatorname{Max})$

Fig. 8. Influence of the pressure difference between water and air on the pulsation of mist flow.

supply pipe into the premix section and when $P_{w^{\prime}}$ $<P_{m}$, this water is discharged from the nozzle as a mist stream. This is the pulsation phenomenon.

The effects of $Q_{w}$ and the pressure different $\Delta P$ on the pulsation of the mist stream are shown in Fig. 8. According to the diagram, little or no pulsation occurs when $P_{w^{\prime}}(\min )>P_{m}(\max )$. Therefore, $P_{w^{\prime}}(\min )=P_{m}(\max )$ can be regarded as the pulsation limit. When an orifice (nozzle orifice) is attached to the tip of the water pipe, the pulsation limit shifts toward the low end of the water flow range.

Since the continuously cast slab has a very large heat capacity, its cooling is rarely affected by the pulsation of the mist stream.

\section{Proper Mist Cooling Conditions}

When practically applying mist cooling, it is important to atomize a water stream uniformly into

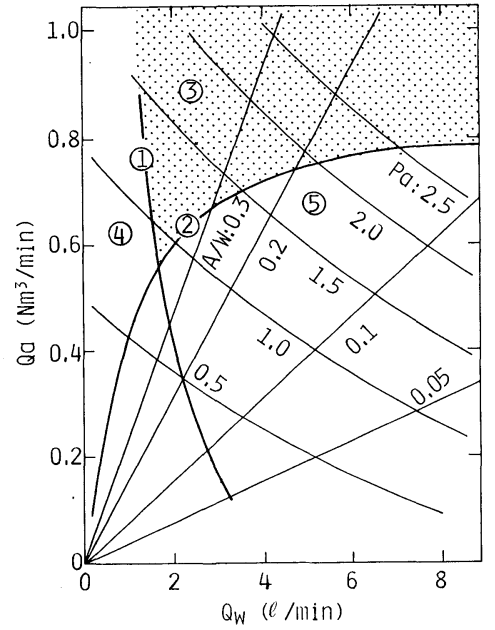

(1): Limitation of pulsation

(2): Limitation of fine mist (Water droplet diameter is smaller than $100 \mu \mathrm{m}$.

(3): Stable region of mist flow

(4): Pulsation region of mist flow

(5): Coarse mist region

Diameter of nozzle orifice: $4 \mathrm{~mm}$

$S: \quad 2.5 \mathrm{~mm}$ (See Fig. 4)

$P_{a}:$ Air pressure in header $\left(\mathrm{kgf} / \mathrm{cm}^{2}-\mathrm{G}\right)$

$Q_{a}, Q_{w}, A / W:$ See Fig. 5

Fig. 9. An example of atomization states of mist flow ejected from a practical mist nozzle.

a stable mist stream and to reduce the cost of mist cooling. The former prerequisite can be easily met by increase of air-water mass flow ratio $Q_{a} / Q_{w}$ (or $A / W)$ or the speed of air flow. This, however, results in increased air cost. Experiment was thus run to determine the relations that would satisfy the optimum conditions between the air and water flow rates as shown in Fig. 9.

In Fig. 9, the fine mist limit (2) is the state in which water is judged to be almost uniformly atomized by visual observation and tactile examination of impingement or in which the diameter of water droplets is about $100 \mu \mathrm{m}$ or less [refer to Figs. 5(2) and (3)]. The pulsation limit (1), on the other hand, is the phenomenon described in Section III. 2. The condition of the mist in the region (3) where these two limits are satisfied is called "a good mist" here. The diagram shows that a good mist can be obtained when $A / W$ or $P_{a}$ is increased or the energy of air injected into the nozzle is increased.

\section{Water Volume Control}

It requires more wide range of cooling capacity for the caster which will cast many grades and size of steel slabs. This can be achieved by expanding the variable range of water flow rate $Q_{w}$. The variable range of $Q_{w}$ in mist cooling is subject to the following constraints:

Lower limit:

1) Uniform distribution of water in zone $\rightarrow$ Measure against difference in head

2) Stability of water atomization (mist stream) $\rightarrow$ 
Measure against pulsation.

Upper limit:

1) Water and air supply cability $\rightarrow$ Limit of economy

2) Atomization of water $\rightarrow$ Maximum atomization capability.

Generally, the condition of the mist stream is strongly affected by the construction of the nozzle (including the nozzle orifice) and the flow rate and pressure of both water and air, as shown in Fig. 9. These relations, experimentally determined, are shown in Fig. 10. If the air pressure $P_{a}$ and air flow rate $Q_{a}$ are set at $2 \mathrm{kgf} / \mathrm{cm}^{2}-\mathrm{G}$ and $0.6 \mathrm{Nm}^{3} / \mathrm{min}$, respectively, for instance, the water flow rate $Q_{w}$ can be controlled over the range of 1.4 to $15 \mathrm{l} / \mathrm{min}$. The water flow rate of up to about $18 \mathrm{l} / \mathrm{min}$ can be used at the slight expense of the mist condition (drop in $Q_{a}$ ). The $Q_{w}$ ratio of $1.4: 18$ is equivalent to the water flow rate ratio of $1: 13$ and the heat transfer coefficient ratio of $1: 8$ (the heat transfer coefficient $h$ is assumed to be $h \infty Q_{w}^{0.8}$.)

\section{Practical Application Results of New Nozzles}

The new nozzles described in this report are practically applied on continuous slab casters at Nippon

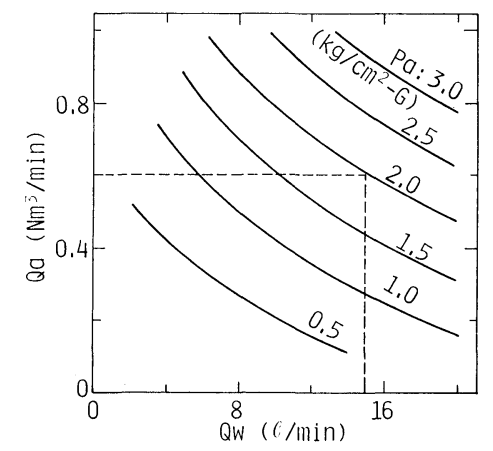

$Q_{a}, Q_{w}:$ See Fig. 5

$P_{a}:$ See Fig. 9

Fig. 10. Control range of the water flow of a practical mist nozzle with wide controllability. (This nozzle is different from one in Fig. 9.)
Steel Corp. The service purposes and application zones of the new nozzles, the main specifications of the cooling devices employed, etc., are given in Table 1. The purposes for which the new nozzles are adopted vary from caster to caster, except that of preventing nozzle clogging. Mist nozzles are used for the primary purpose of improving slab quality and the secondary purpose of preventing nozzle clogging and widening controllability of cooling, while air-injection nozzles are installed for the only purpose of preventing nozzle clogging.

\section{Effect in Reduction of Nozzle Clogging}

The cases of spray nozzle clogging before the adoption of the new nozzles are shown in Fig. 11. The diagram indicates that the nozzle clogging rate increases with decreasing nozzle outlet diameter. Since the water flux in the secondary cooling zones generally decreases with increasing distance from the mold, nozzles with small water discharge rate or small outlet holes are used in the zone IV or zone $\mathrm{V}$ and subsequent secondary cooling zones. As a result, many slab casters are likely to have frequent nozzle clogging in those zones (refer to the Hirohata caster in Table 2) and hence use the new nozzles in those zones for the purpose of preventing nozzle clogging.

The incidence of nozzle clogging after the adoption of the new nozzles is shown in Table 2. It is evident from the table that the new nozzles are far lower in the clogging rate than the conventional spray nozzles and require less maintenance than the conventional spray nozzles.

\section{Cooling Characteristics of Mist Cooling}

The surface temperatures of slabs mist-cooled or flat-spray-cooled and measured in the same places before and after the modification are shown in Fig. 12. The temperature patterns indicate the difference in cooling mechanism between the two cooling methods. Of course, there are many other temperature patterns in addition to these typical patterns

Table 1. Demands for mist cooling and the main specifications of cooling devices for the secondary cooling zone.

\begin{tabular}{|c|c|c|c|c|c|c|}
\hline \multicolumn{3}{|c|}{ Name of GCM } & Oita, Nos. 4,5 & Sakai, No. 1 & Kimitsu, No. 3 & Hirohata, No. 1 \\
\hline \multirow{4}{*}{$\begin{array}{l}\text { Demand } \\
\text { (@): Main) }\end{array}$} & \multirow{4}{*}{\multicolumn{2}{|c|}{$\begin{array}{l}\text { Mild cooling } \\
\text { Uniform cooling } \\
\text { Prevention of clogging } \\
\text { Wide controllability of cooling }\end{array}$}} & () & () & - & - \\
\hline & & & (2) & () & (O) & $\bigcirc$ \\
\hline & & & () & (?) & () & () \\
\hline & & & - & - & (2) & $\mathrm{O}$ \\
\hline \multicolumn{3}{|c|}{ Mist cooling zone } & Nos. 4 to 6 & Nos. 4 to 7 & Nos. 4 to 7 & No. 6 \\
\hline \multicolumn{3}{|l|}{ Nozzle type } & Mist & Mist & Mist & Air-injection \\
\hline \multicolumn{3}{|c|}{ Diameter of header orifice $(\mathrm{mm})$} & 6 & 4 & 4 & - \\
\hline \multirow{2}{*}{\multicolumn{2}{|c|}{ Nozzle arrangement }} & Nozzle spacing (mm) & 400 to 540 & 325 & 200 to 500 & one nozzle/header \\
\hline & & Nozzle distance $(\mathrm{mm})$ & 200 to 260 & 120 & 150 to 300 & 350 \\
\hline \multirow{2}{*}{\multicolumn{2}{|c|}{$\begin{array}{l}\text { Water flow range } \\
\text { (l/min-nozzle) }\end{array}$}} & Loose side & 1 to 9 & 0.9 to 11 & 1.3 to 17 & 7 to 21 \\
\hline & & Fixed side & 1 to 12 & 1.3 to 11 & 1.3 to 17 & 10 to 33 \\
\hline \multicolumn{2}{|c|}{$\begin{array}{l}\text { Start of mist coling } \\
\text { operation }\end{array}$} & $\begin{array}{l}\text { No. 4: } \text { August, } 1980 \\
\text { No. 5: }\end{array}$ & & $\begin{array}{l}\text { January, } \\
1981\end{array}$ & $\begin{array}{l}\text { January, } \\
1982\end{array}$ & July, 1979 \\
\hline
\end{tabular}




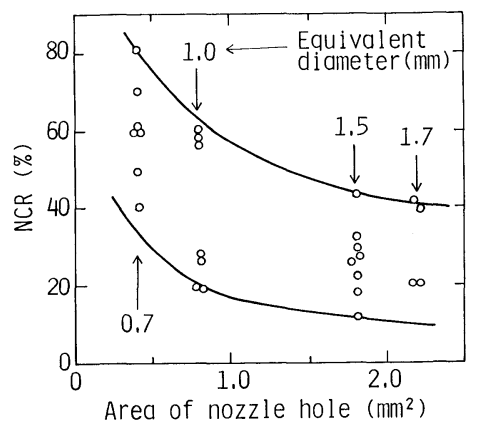

(1) Kimitsu No:2 CCM ( (B))

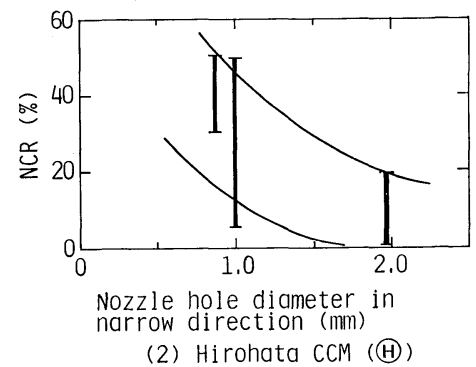

(1) Nozzle: (B) Flat and full cone spray (ii) Flat spray

(2) NCR : Ratio of clogged nozzles in each segment

(3) Working time of nozzles: (B) About 5 months (11) About 10 days

Fig. 11. Examples of clogging of spray nozzles used in the secondary cooling zone.

Table 2. Comparison of clogging and maintenance of mist nozzles with those of spray nozzles.

\begin{tabular}{|c|c|c|c|}
\hline & Works & Mist cooling zone & Spray cooling zone \\
\hline \multirow{4}{*}{$\begin{array}{l}\text { bo } \\
. \\
0 \\
0 \\
0 \\
0\end{array}$} & Oita & Little & Use of walking bar \\
\hline & Sakai & Little & About $20 \% / 4$ months \\
\hline & Kimitsu & Little & About $20 \% / 5$ months \\
\hline & Hirohata & $0.89 \% /$ half-month* & $\begin{array}{l}\text { I : } 1.5, \text { II }: 2.5, \\
\text { III }: 14.2, \text { IV }: 17.4 \text { and } \\
\text { V }: 19.8 \% / \text { half-month }\end{array}$ \\
\hline \multirow{4}{*}{ 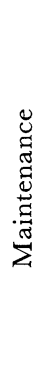 } & Oita & $\begin{array}{l}\text { Exchange of } 15 \\
\text { nozzles/2 months } \\
\text { (About } 500 \text { nozzles/ } \\
\text { GCM) }\end{array}$ & Use of walking bar \\
\hline & Sakai & Check/half-month & Check/cast \\
\hline & Kimitsu & $\begin{array}{l}\text { No clogging ob- } \\
\text { served so far }\end{array}$ & $\begin{array}{l}\text { Exchange of clogged } \\
\text { nozzles } / 3 \text { to } 12 \text { months }\end{array}$ \\
\hline & Hirohata & $\begin{array}{l}\text { Cleaning of clogged } \\
\text { nozzles/half-month* }\end{array}$ & $\begin{array}{l}\text { Cleaning of clogged } \\
\text { nozzles/half-month }\end{array}$ \\
\hline
\end{tabular}

* Air-injection nozzle

(refer to Fig. 7 in Ref. 6)). The diagram shows that the slab is intensely cooled by contact with the rolls in the case of mist cooling, too.

The average heat transfer coefficient $h$ measured in the same zone of a slab caster under mist cooling and spray cooling (before the modification) are shown in Fig. 13. The following can be known from the diagram:

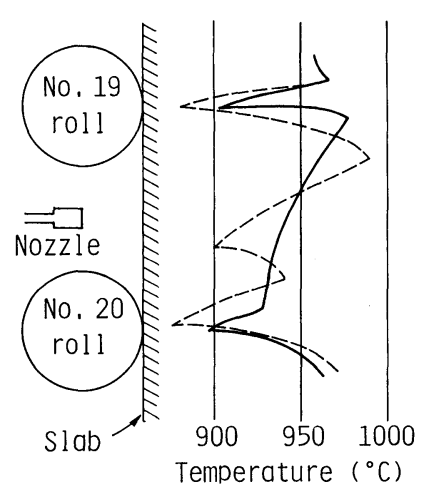

- $:$ Mist cooling

-.--: Spray cooling

Casting speed: $1.2 \mathrm{~m} / \mathrm{min}$

Fig. 12. Examples of the slab surface temperature change measured by stud-welded theathed thermocouples (Oita No. 5 GCM).

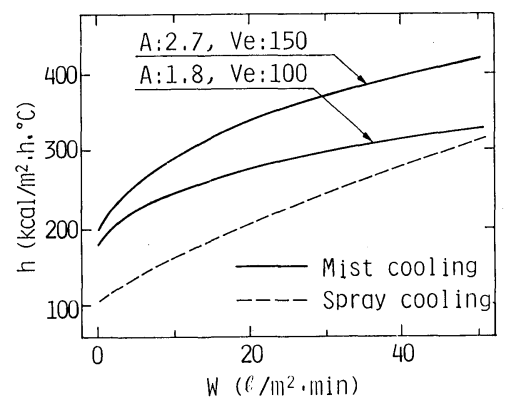

$A$ : Average impinged air flux $\left(\mathrm{Nm}^{3} / \mathrm{m}^{2} \cdot \min \right)$ $V_{e}:$ See Fig. 5

Fig. 13. Relationship between average heat transfer coefficient, $h$ and average impinged water flux, $W$ in the secondary cooling zone ( $\mathrm{V}$ zone of Oita No. 5 CCM).

(1) When the discharged water flux $W$ is the same, the heat transfer coefficient in mist cooling $h_{\mathrm{mist}}$ is larger than the heat transfer coefficient in spray cooling $h_{\text {spray }}$.

(2) When $W$ is the same, $h_{\text {mist }}$ increases with increasing air discharge speed.

Phenomenon (1) is considered to result from the cooling effect of air and from the increase in heat transfer surface area by the mist stream. With spray cooling, the water pocketed by the rolls falls from the edges of the slab to intensely cool the edges. For mist cooling, in contrast, the water droplets are blown away by the air and little or no water is pocketed by the rolls. As a result, the slab edges are not so intensely cooled as is the case with spray cooling (refer to Fig. 9 in Ref. 6)).

\section{Problems of Mist Cooling}

(1) Reduction in Mist Cooling Cost

As compressed air of 2 to $3 \mathrm{kgf} / \mathrm{cm}^{2}-\mathrm{G}$ in header pressure is used for the mist cooling method developed, the equipment and operating costs of the air system are high (3 to $10 \mathrm{kWh} / \mathrm{t}$-slab). These high costs must be reduced (for example, by using such a nozzle that water and air is mixed outside the nozzle). 
(2) Prevention of Intense Cooling by Rolls

Even if the mist cooling method is adopted, the slab is intensely cooled by contact with the rolls (refer to Fig. 12). Therefore, it is necessary to reduce the heat transfer from the slab to the rolls (for example, by raising the temperature of the rolls or covering the rolls with a heat insulating material). (3) Mild Cooling of Slab Edges

Even if the mist cooling method is adopted, the slab edges are intensely cooled. This calls for technology that can easily change the water flux distribution according to the slab width (for instance, use of variable water distribution nozzles or installation of mist stream shutoff devices).

\section{Conclusions}

The authors developed mist cooling systems for the secondary cooling zones of continuous slab casters for the main purposes of uniform and mild cooling of the slab and preventing nozzle clogging. Those systems have been in service for the slab casters of the Oita, Sakai, Kimitsu and Hirohata Works of Nippon Steel Corp. The main features of the systems are the followings :

(1) A premix nozzle was developed as mist nozzle and a commercial flat spray nozzle was modified as air-injection nozzle.

(2) Nozzle cloggings are very seldom in the zones where the new nozzles are used.

(3) The changes of slab surface temperature are smaller in mist cooling than with spray cooling. When the discharged water flow rate is the same, mist cooling provides a larger cooling capacity than spray cooling.

\section{Nomenclature}

$Q_{w}, Q_{a}$ : discharge flow rate of water $(l / \mathrm{min})$ and of air $\left(\mathrm{Nm}^{3} / \mathrm{min}\right)$

$P_{w}, P_{a}$ : pressure of water and air in header $\left(\mathrm{kgf} / \mathrm{cm}^{2}-\mathrm{G}\right)$

$q_{w}$ : amount of collected water ( $l /$ min-area)

$A / W$ : mass flow ratio of air to water $\left(Q_{a} / Q_{w}\right)$ $(-)$

$V_{e}:$ discharge speed of air (mist) $(\mathrm{Nm} / \mathrm{s})$

$S$ : width of discharge hole of mist nozzle ( $\mathrm{mm})$

\section{Acknowledgements}

The authors would like to thank the engineers of continuous casting and heat technology departments, Nippon Steel Corp., for their helpful advices and cooperation in the development of the mist cooling of slab casters.

\section{REFERENGES}

1) T. Matsumiya, T. Saeki, J. Tanaka and T. Ariyoshi: Tetsu-to-Hagané, 68 (1982), 1782.

2) T. Kohno, K. Shima, T. Kuwabara, S. Mizoguchi, T. Yamamoto, H. Misumi and S. Tsuneoka: Tetsu-to-Hagané, 68 (1982), 1764.

3) T. Saeki, S. Ohkuchi, S. Mizoguchi, T. Yamamoto, H. Misumi and S. Tsuneoka: Tetsu-to-Hanané, 68 (1982), 1773.

4) P. Benoit and Ph. Pithois: Continuous Casting of Steel, The Met. Soc., London, (1977), 91.

5) G. Kaestle, H. Jacobi and K. Wünnenberg: Steelmaking Proceedings, Vol. 65, ISS-AIME, Penn., (1982), 251.

6) T. Kohno, K. Shima, T. Kuwabara, T. Yamamoto, M. Wake and S. Tsuneoka: Tetsu-to-Hagané, 68 (1982), 1792.

7) H. Schrewe: Ironmaking Steelmaking, (1981), No. 2, 85.

8) West German Patent No. 281644; Japanese Patent Application No. 54-138824, (1979). 